\title{
Cerebrospinal fluid shunt dynamics in patients with idiopathic adult hydrocephalus syndrome
}

\author{
Jan Malm, Bo Kristensen, Markku Fagerlund, Lars-Owe Koskinen, Jan Ekstedt
}

\begin{abstract}
The objective was to assess CSF dynamics of different shunt constructions in patients with adult hydrocephalus syndrome and correlate these findings to clinical outcome, neuroradiology, and the specifications of the shunts provided by the manufacturer. Thirty four patients with idiopathic adult hydrocephalus (normal pressure hydrocephalus) syndrome were included in a prospective, consecutive case series. A differential pressure valve (Cordis Hakim standard system) was used in 28 patients and a variable resistance valve (Cordis Orbis-Sigma) in six.

A constant pressure infusion method was used; CSF pressure and conductance were determined before surgery. Three months after shunt placement CSF pressure, the "pressure $v$ flow" curve, and gravity induced flow were measured.
\end{abstract}

There was no difference between mean preoperative and postoperative resting CSF pressures in patients with Hakim shunts. The opening pressures of the Hakim shunts were higher than the value proposed by the manufacturer. A pronounced gravity effect induced CSF flow and decrease of the CSF pressure. In functioning variable resistance valves, CSF dynamics normalised postoperatively. There was no gravity effect and the characteristic s shaped "pressure $v$ flow" curve was sometimes seen. Six patients (three differential pressure valves, three variable resistance valves) had non-functioning shunts. Four of these patients were improved after the operation but improvement was transient in three. In all patients, there was no relation between the width of the ventricles and clinical improvement or CSF pressure.

In conclusion, the differential pressure valve system does not behave according to the specifications provided by the manufacturer. A decrease in CSF pressure in patients with this shunt was solely due to the effect of gravity. Eleven per cent of the differential pressure valves and $50 \%$ of the variable resistance valves were non-functioning. In the functioning variable resistance valves, the antisiphon system seems to be effective.

\section{(F Neurol Neurosurg Psychiatry 1995;58:715-723)}

Keywords: cerebrospinal fluid shunt; hydrocephalus; cerebrospinal fluid dynamics
Patients with the idiopathic adult hydrocephalus syndrome (IAHS) ${ }^{12}$ are provided with a shunt device to restore normal CSF dynamics and achieve a substantial functional improvement. Shunt failure, however, due to improper placement, infection, obstruction, breakage, disconnection, or migration of the shunt is of major concern. ${ }^{3}$ The long term characteristics of the shunt may change. ${ }^{4-6}$ Shunt resistance and the corresponding CSF flow may vary according to the length and the diameter of the proximal and distal catheters. ${ }^{4}$ Posture related changes may give a negative intracranial pressure due to a gravity induced flow (siphon effect) with secondary overdrainage, ${ }^{7-10}$ hygroma, or subdural haematoma.

The standard of CSF shunts may be defined in terms of opening and closing pressure, antireflux properties, leakage, pressure and flow characteristics, mechanical durability, and siphoning effect. ${ }^{11}{ }^{12}$ These variables are determined in bench tests by the manufacturer before the operation but many valves have been found not to respond according to their specifications. . $^{4-6}$

Shunt function cannot be assessed in patients with IAHS by clinical examination or by pumping the valve. ${ }^{13}$ There is no criterion standard for in vivo measurements of shunt function. Computed tomography, MRI, ${ }^{14-16}$ doppler ultrasonography, ${ }^{17}$ radionuclide studies, ${ }^{18-20}$ and thermography have been used to measure shunt flow in vivo. These methods do not take into consideration the importance of pressure and flow characteristics of the shunt and the CSF system. With a CSF infusion technique, it is possible to assess whether CSF dynamics have been normalised postoperatively together with the properties of the shunt system, including the degree of gravity induced CSF flow.

We prospectively investigated 34 patients with IAHS given ventriculoperitoneal shunts. Dynamics of CSF were evaluated preoperatively and three months after the operation and compared with shunt characteristics provided by the manufacturer, clinical response, pressure $v$ flow curves, changes in CSF pressure, and gravity induced flow.

\section{Materials and methods} PATIENTS

The study population consisted of 34 patients (25 men and nine women (mean age (SD) $71 \cdot 7(5 \cdot 1)$ years)) with IAHS. ${ }^{21-28}$ The diagnosis was based on (a) a gait disturbance as a predominant and obligate symptom; $(b)$ mental 
impairment, or urinary incontinence, or both (ranging from not clinically present to severe disturbances); (c) CT showing dilatation of the lateral ventricles without severe cortical atrophy; (d) absence of another disease that might explain the clinical symptoms or radiological findings. Informed consent for all aspects of the study was obtained from all the patients.

An extensive investigation was performed in each patient to exclude other causes of gait disorder or dementia. The results of ancillary investigations and clinical characteristics, and reasons for exclusion of patients are reported elsewhere. ${ }^{29}$ Dynamic investigations of CSF and CT were performed in all patients before surgery and at three months after shunting. None of the patients had any symptoms or signs of postoperative overdrainage. The CT did not show any intracranial haematomas. All patients were investigated with the shunt pumping test, ${ }^{13}$ but there was no evidence of proximal or distal catheter obstruction.

\section{SURGICAL METHOD}

A variable resistance valve (Cordis OrbisSigma) was used in six patients. A differential pressure valve (Cordis Hakim standard system; medium opening or closing pressure $0 \cdot 8-1 \cdot 2 \mathrm{kPa}$ ) was used in 28 patients. The shunt was introduced by a ventriculoperitoneal approach. No shunt was revised during the study period.

DEFINITIONS AND UNITS OF MEASUREMENT SI units have been used. Because a variety of units are cited in the medical literature, the following conversion factors are given:

Pressure: $1 \mathrm{kPa}=102 \mathrm{~mm} \mathrm{H}_{2} \mathrm{O}=7.5 \mathrm{~mm} \mathrm{Hg}$. Conductance: $1 \mathrm{~mm}^{3} \cdot \mathrm{kPa}^{-1} \cdot \mathrm{s}^{-1}=6 \times 10^{-3} \mathrm{ml}$ $\left(\mathrm{cm} \mathrm{H}_{2} \mathrm{O}\right)^{-1} \cdot \mathrm{min}^{-1}=8 \times 10^{-3}(\mathrm{~mm} \mathrm{Hg})^{-1}$. $\min ^{-1}$.

Resistance: the inverse of conductance.

Flow: $1 \mathrm{~mm}^{3} \cdot \mathrm{s}^{-1}=3.6 \mathrm{ml} / \mathrm{h}=0.06 \mathrm{~cm}^{3} \cdot \mathrm{min}^{-1}$

The following abbreviations have been used: $\mathrm{Pc1}=$ CSF pressure preoperatively; $\mathrm{Pc2}=$ CSF pressure postoperatively; $\mathrm{Pc} 3=\mathrm{CSF}$ pressure postoperatively after sitting for 10 minutes; ICP = intracranial pressure; $\mathrm{HP}=$ hydrostatic pressure (length of gravity effected CSF column); OP = opening pressure of the shunt; $P P=$ perfusion pressure of CSF (the driving force of CSF flow between the ventricles and the abdomen); Gop = conductance of CSF outflow; $Q=C S F$ flow; $R=$ resistance in the shunt system.

DYNAMIC STUDIES ON CSF

The CSF dynamic studies ${ }^{60-32}$ were performed preoperatively and at three months after operation. Briefly, at 0800, after 12 hours of bed rest, two needles (outer diameter $1.2 \mathrm{~mm}$ ) were inserted in the L3-L4 interspace. Free passage was assessed by aspiration of $2 \mathrm{ml} \mathrm{CSF}$, which was replaced with artificial CSF. The patient was then placed supine with the zero pressure reference level at the cranial sagittal centre. Drainage of CSF and infusion of artificial CSF was made to and from a continuously weighed bottle. The pressure in the bottle was regulated via an electronic control system acting on the fluid within it by means of the air pressure from a pump.

The preoperative CSF pressure (Pc1) was determined when the resting recording had been stable for at least 10 minutes, usually after 30-60 minutes of recording. The conductance of the CSF outflow pathways (Gop) was determined by applying different pressure levels to the CSF space while recording the resulting inflow of artificial CSF into the patient. Thus within a few minutes a stable flow at a stable pressure was obtained. Usually, three different pressure/flow values were aimed at. The volume accounting method was used to calculate the pressure/ flow relation. The slope for the pressure/flow values is equal to the Gop.

To avoid errors due to body position or physical exercise, the investigation after operation was started with the CSF infusion. There was no external pressure on the distal catheter of the shunt. The pressure/flow curve was an indicator of the amount of CSF eliminated via the shunt because the quantity eliminated through the natural pathways was known from the preoperative Gop measurement (fig 1). Usually three assessments were appropriate to determine the pressure/flow relation in differential pressure shunts. The pressure/flow
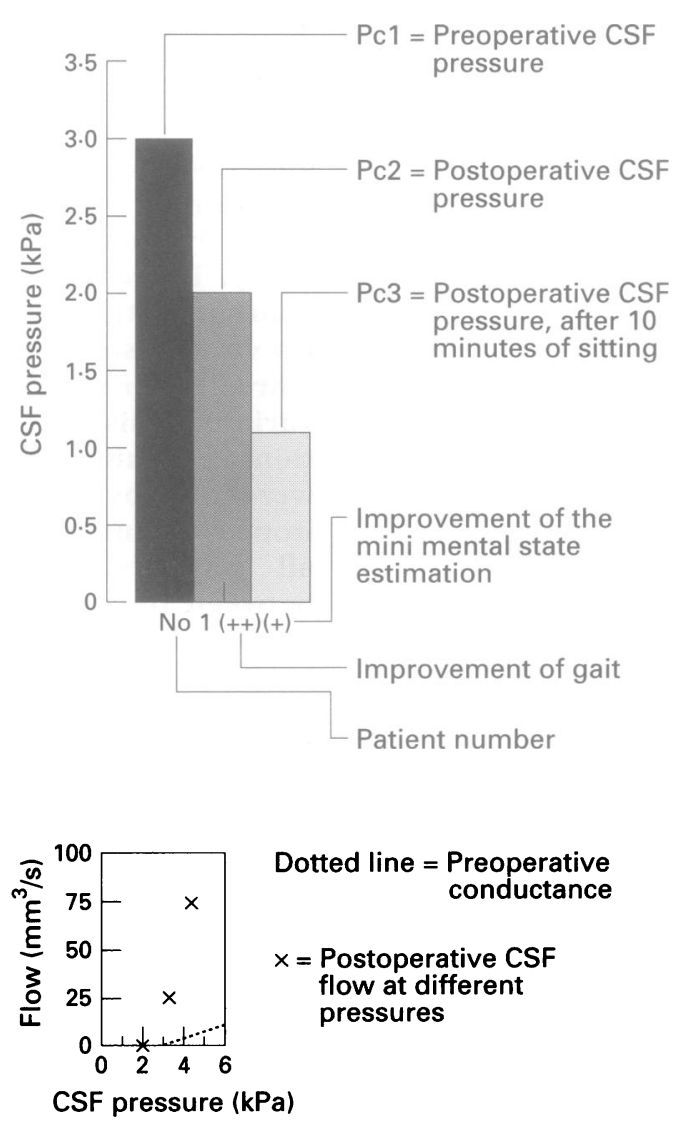

Figure 1 How to read the figures. CSF pressure and pressure $v$ flow characteristics preoperatively and postoperatively. 
characteristics of the variable resistance shunts are $S$ shaped and multiple pressure/ flow values were obtained. The opening pressure of the differential pressure shunts could be defined as the point where the pressure/ flow curve started to increase steeply (fig 1).

After the CSF infusion test, the CSF pressure declined spontaneously. The postoperative CSF pressure (Pc2) was determined when the resting recording had been stable for at least 10 minutes, usually after $30-60 \mathrm{~min}$ utes of recording.

The gravity (or siphoning) effect of the shunt was tested at the end of the investigation. Patients were in the sitting position for 10 minutes, after which they were again laid supine. The corresponding CSF pressure (Pc3) was registered using the same zero pressure reference level as above. In a healthy control or a shunted patient without a gravity effect, the Pc3 is the same as Pc2 (fig 2A). In a shunted patient with a gravity effect, Pc3 should be lower than Pc2 (fig 2B).

ASSESSMENT OF SHUNT FUNCTION

Four variables were estimated for each shunt: (1) The difference between the CSF pressure preoperatively and postoperatively $(\mathrm{Pc1}-\mathrm{Pc} 2)$. (2) The difference between the preoperative CSF pressure and the postoperative CSF pressure after sitting for 10 minutes ( $\mathrm{Pcl}$ Pc3). (3) The gravity effect (Pc2 - Pc3). (4)

Figure 2 The CSF pressure recording before, during, and after sitting for 10 minutes in a patient without a shunt $(A)$ and in a patient with a shunt (B).

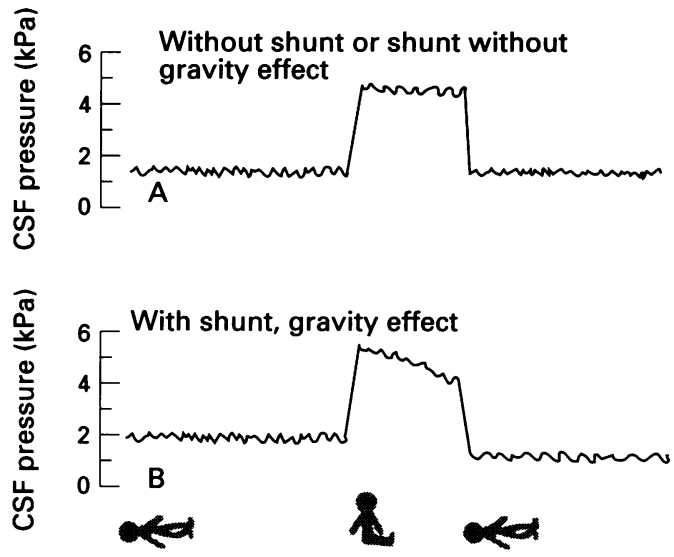

Table 1 Preoperative (Pc1) and postoperative (Pc2 and Pc3) mean values of CSF pressures in patients with Hakim and Orbis-Sigma shunts

\begin{tabular}{|c|c|c|c|c|}
\hline & Valve system & $n$ & Mean $(95 \% C I)(k P a)$ & Pvalue \\
\hline $\begin{array}{l}\text { CSF pressure, } \\
\text { preoperative }(\mathrm{Pcl})\end{array}$ & $\begin{array}{l}\text { Hakim } \\
\text { Orbis-Sigma }\end{array}$ & $\begin{array}{r}28 \\
6\end{array}$ & $\begin{array}{l}1 \cdot 9(1 \cdot 7-2 \cdot 1) \\
2 \cdot 3(1 \cdot 7-2 \cdot 9)\end{array}$ & \\
\hline $\begin{array}{l}\text { CSF pressure, } \\
\text { postoperative (Pc2) }\end{array}$ & $\begin{array}{l}\text { Hakim } \\
\text { Orbis-Sigma }\end{array}$ & $\begin{array}{r}28 \\
6\end{array}$ & $\begin{array}{l}1 \cdot 9(1 \cdot 7-2 \cdot 1) \\
1 \cdot 7(1 \cdot 2-2 \cdot 2)\end{array}$ & \\
\hline $\begin{array}{l}\text { Difference } \\
\quad(\mathrm{Pc} 1-\mathrm{Pc} 2)\end{array}$ & Hakim & $\begin{array}{r}28 \\
6\end{array}$ & $\begin{array}{l}0 \cdot 0(-0.1 \text { to } 0 \cdot 1) \\
0.6(0 \cdot 0-1 \cdot 2)\end{array}$ & $\begin{array}{l}\text { NS } \\
\text { NS }\end{array}$ \\
\hline $\begin{array}{l}\text { CSF pressure, } \\
\text { postoperative (Pc3) }\end{array}$ & $\begin{array}{l}\text { Hakim } \\
\text { Orbis-Sigma }\end{array}$ & $\begin{array}{r}28 \\
6\end{array}$ & $\begin{array}{l}1 \cdot 3(1 \cdot 2-1 \cdot 4) \\
1 \cdot 6(1 \cdot 0-2 \cdot 2)\end{array}$ & \\
\hline $\begin{array}{l}\text { Difference } \\
\quad(\text { Pc1 - Pc3) }\end{array}$ & $\begin{array}{l}\text { Hakim } \\
\text { Orbis-Sigma }\end{array}$ & $\begin{array}{r}28 \\
6\end{array}$ & $\begin{array}{l}0.6(0.4-0.8) \\
0.7(0-1 \cdot 4)\end{array}$ & $\begin{array}{l}<0.0001 \\
\text { NS }\end{array}$ \\
\hline $\begin{array}{l}\text { Difference (gravity effect) } \\
\text { (Pc2 - Pc3) }\end{array}$ & $\begin{array}{l}\text { Hakim } \\
\text { Orbis-Sigma }\end{array}$ & $\begin{array}{r}28 \\
6\end{array}$ & $\begin{array}{l}0.6(0.5-0.7) \\
0.1(-0.2 \text { to } 0.4)\end{array}$ & $\begin{array}{l}<0.0001 \\
\text { NS }\end{array}$ \\
\hline
\end{tabular}

The preoperative pressure $v$ flow curve (the conductance) compared with the postoperative pressure $v$ flow curve of the shunt.

A shift $\geqslant$ the $95 \%$ confidence interval $(95 \% \mathrm{CI})$ on the differences between the CSF pressures was taken as an indicator of alteration.

\section{VARIABLES OF SURGICAL OUTCOME}

The subject was asked to walk 25 metres as fast as possible. The task was repeated three times and the mean gait velocity $(\mathrm{m} / \mathrm{s})$ was calculated. The gait was videotaped. The preoperative recording was compared with the recording at three months after operation. The recordings were rated as same, better, or worse by two physiotherapists independently on the six items: gait initiation, rhythmic movements, step size, shuffling, wide base, and turning. ${ }^{33} 34$ If at least four items were rated as better, the video recording was classified as improved. The between rater reliability was high (Spearman rank correlation $r^{2}=0.96$ ). The gait was classified as markedly improved if the video recording was improved and the postoperative gait velocity was $>25 \%$ faster.

The mini mental state examination (MMSE) $^{35}$ was performed by one of the neurologists. A shift $\geqslant$ the $95 \%$ CI was taken as indicator of improvement.

\section{NEURORADIOLOGY}

All measurements on CT were done by a senior neuroradiologist without knowledge of the patients' CSF dynamics. The width of the third ventricle was measured in $\mathrm{mm}$ and the lateral ventricles measured as a ventricular index. ${ }^{36}$

\section{STATISTICAL METHODS}

Statistical analyses were conducted with the JMP program for the Macintosh computer. ${ }^{37}$ Comparisons of variables before and after operation were evaluated by a paired $t$ test; 95\% CIs were calculated. Linear regression analyses or analyses of variance (ANOVA) were performed when appropriate.

\section{Results}

DIFFERENTIAL PRESSURE VALVE (CORDIS HAKIM STANDARD SYSTEM)

Table 1 shows the mean values of $P c 1, P c 2$, and Pc3. There were no differences between the preoperative and postoperative pressures $(\mathrm{Pc1}-\mathrm{Pc} 2)$. There was a significant gravity effect.

Considering that the main objective of shunting patients with IAHS is to decrease CSF pressure, four types of responses could be seen: (1) (fig 3A; 11 patients): the decrease of Pc1 - Pc2 was $\geqslant$ upper $95 \%$ CI, which indicates a pronounced reduction in CSF pressure postoperatively. In six of the patients, Pc 3 was $<1.0 \mathrm{kPa}$. There was a prominent gravity effect $\left(P_{c} 2-\operatorname{Pc} 3\right)$ and the pressure $v$ flow curves showed increasing flow with increasing pressure, well above the CSF drainage preoperatively. Patient 10 had a very 
Figure $3 A-D$ CSF

dynamics of Hakim shunts

before and after operation.

For further explanations see the results section.
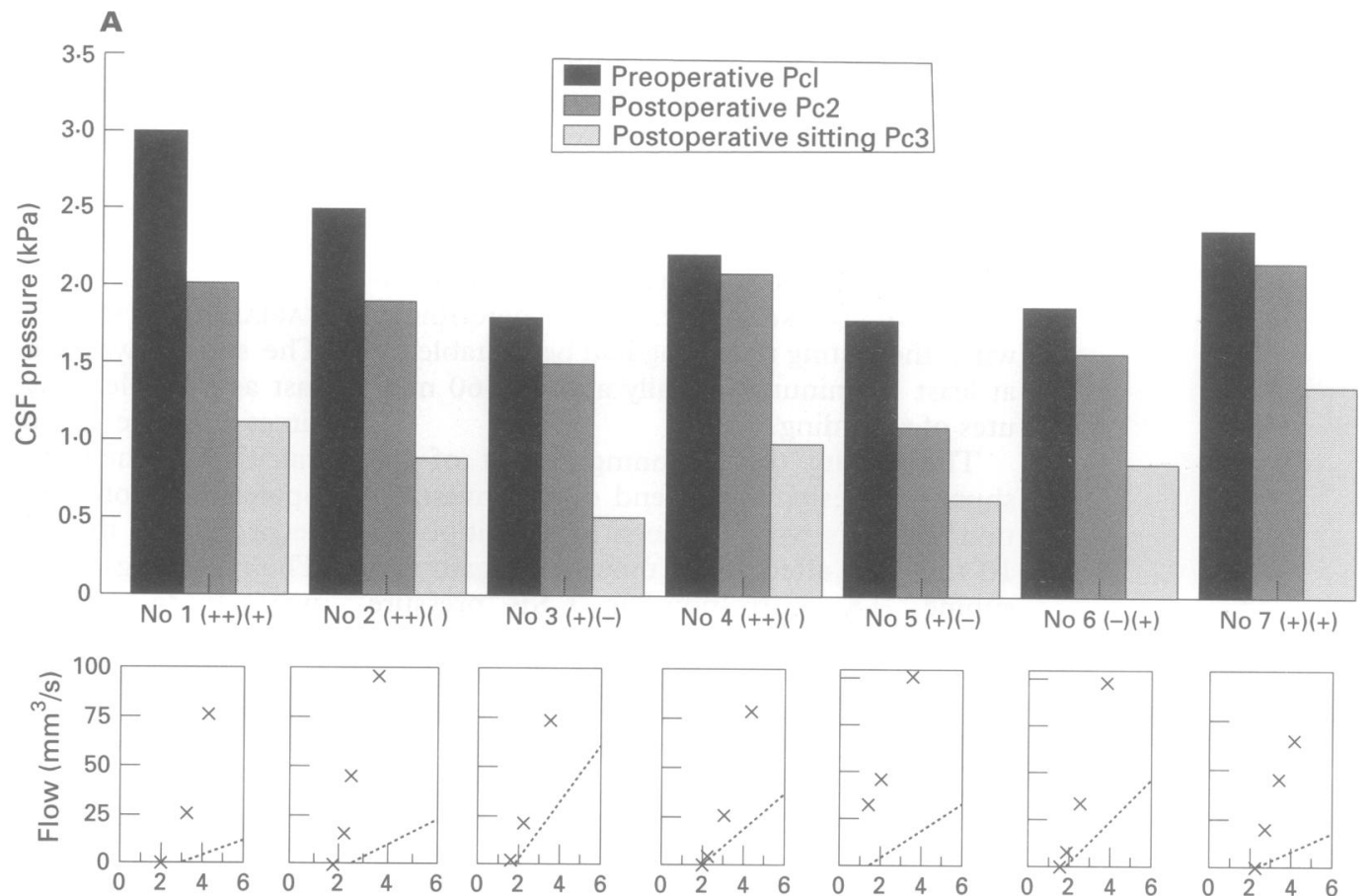

No $4(++)()$

No $5(+)(-)$
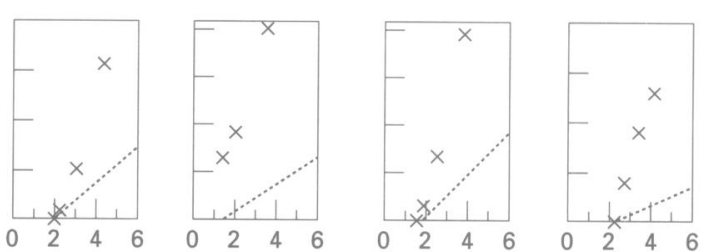

CSF pressure $(\mathrm{kPa})$

A (continued)

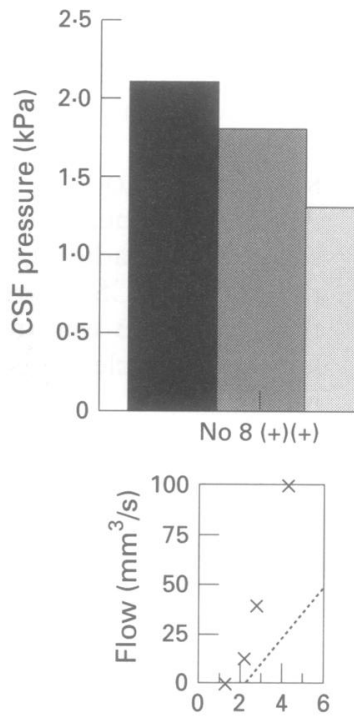

CSF pressure $(\mathrm{kPa})$
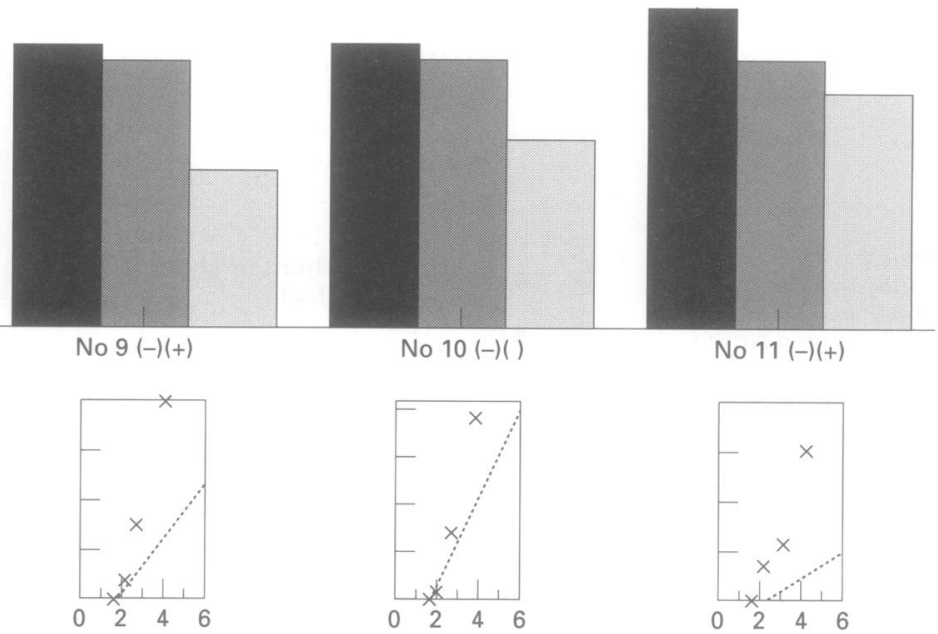

No $11(-)(+)$

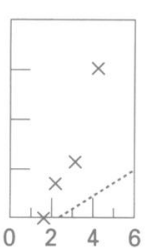

B
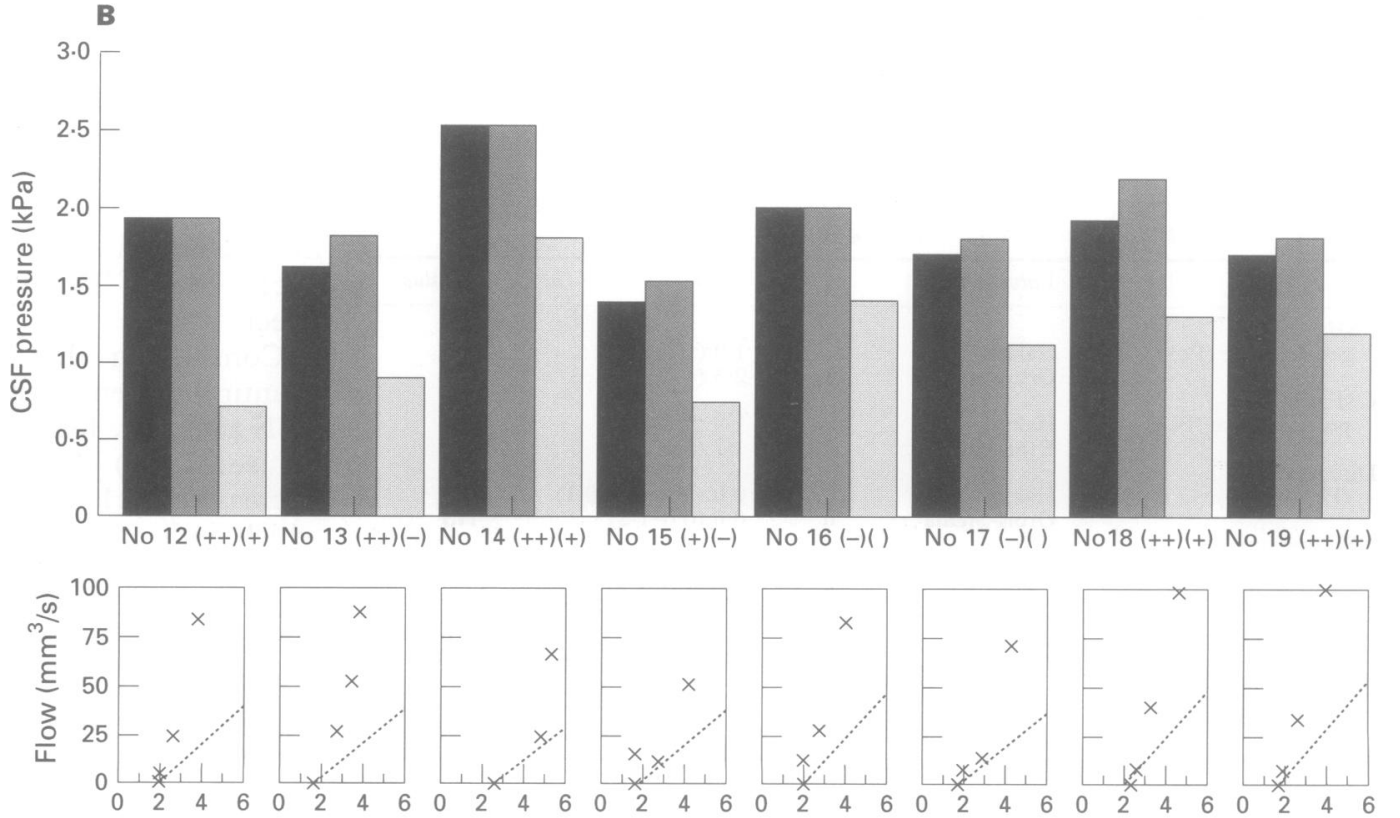

CSF pressure $(\mathrm{kPa})$ 

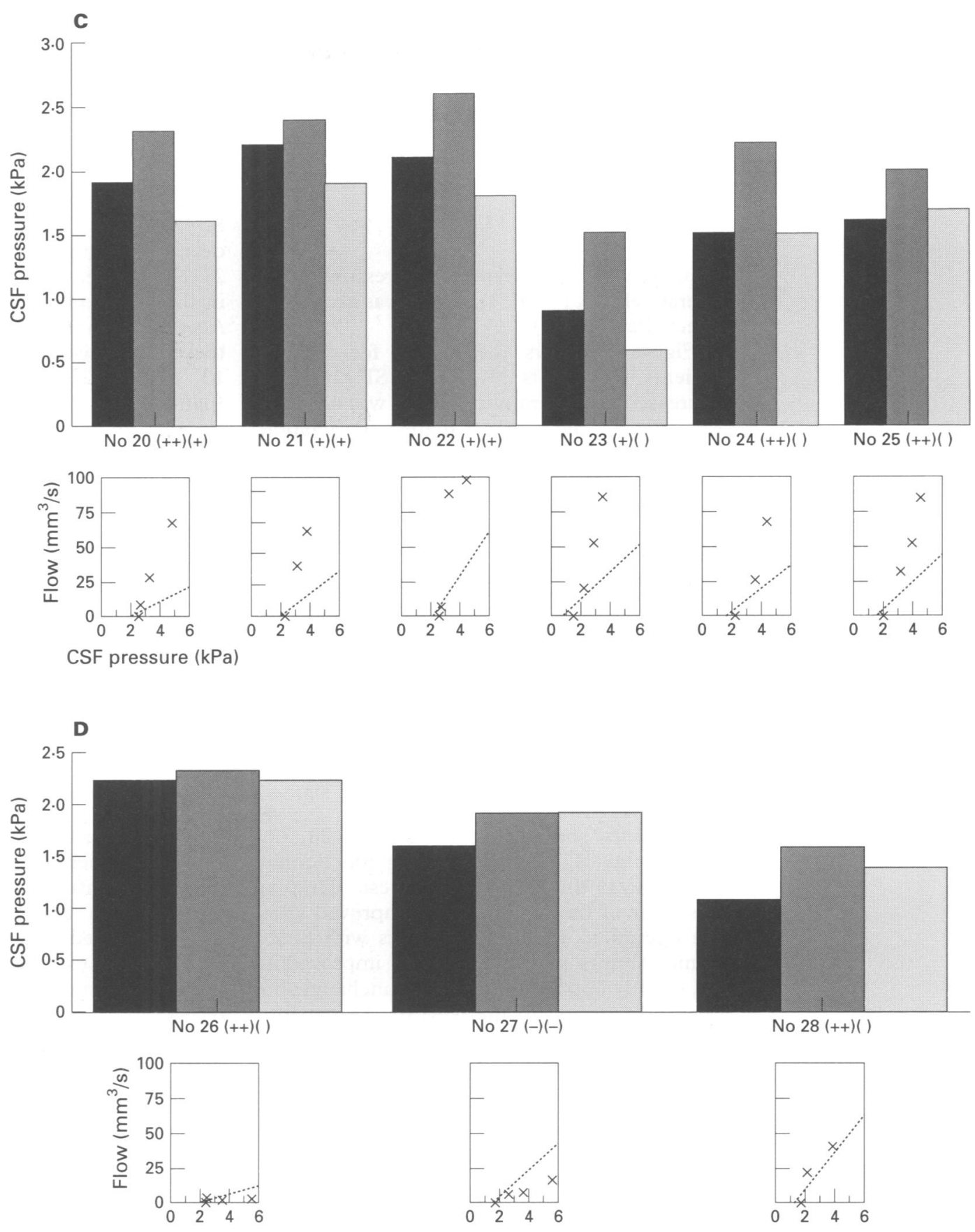

$\mathrm{CSF}$ pressure $(\mathrm{kPa})$

high conductance preoperatively and the shunt did not improve the pressure flow response despite a high differential valve pressure. Gait was not improved in four patients and MMSE was not improved in five. (2) (fig 3B; eight patients): the Pc1 - Pc3 decreased between the upper and lower 95\% CI and Pc1 - Pc2 was unchanged. The gravity effect and pressure $v$ flow curves show that there was a flow through the shunt. In three of the patients, Pc3 was $<1 \mathrm{kPa}$. Gait was not improved in two patients and MMSE was not improved in four. (3) (fig 3C; six patients): Pc1 - Pc3 was unchanged or slightly decreased postoperatively and Pc1 - Pc2 was increased. This indicates that there was no decrease in the preoperative CSF pressure, even after the patient has been sitting in the postoperative assessment. As shown by the gravity effect and the pressure $v$ flow curves the shunts were functioning. In one of the patients, Pc 3 was below $1 \mathrm{kPa}$. Gait improved in all patients whereas MMSE deteriorated or was unchanged in three patients. (4) (fig 3D; three patients): Pc1 - Pc3 was unchanged or slightly increased and $\mathrm{Pc1}-\mathrm{Pc2}$ was increased. This indicates that there was no postoperative change in CSF pressure compared with the preoperative registrations. The shunts in these patients were not functioning as the gravity effect was absent and the pressure $v$ flow curves indicated CSF drainage only via the natural pathways.

\section{VARIABLE RESISTANCE VALVE (CORDIS} ORBIS-SIGMA) SYSTEM

Table 1 shows the mean values of $\mathrm{Pc1}, \mathrm{Pc} 2$, and Pc3. There was a tendency towards 
Table 2 Width of the ventricles preoperatively and postoperatively

\begin{tabular}{lcclll}
\hline & $\begin{array}{l}\text { Preoperative } \\
\text { Mean }(95 \% \text { CI })\end{array}$ & $\begin{array}{l}\text { Postoperative } \\
\text { Mean }(95 \% \text { CI })\end{array}$ & $\begin{array}{l}\text { Difference } \\
\text { Mean }(95 \% \text { CI })\end{array}$ & P value \\
\hline $\begin{array}{l}\text { Ventricular } \\
\text { index }\end{array}$ & $0.33(0.31-0.35)$ & $0.31(0.29-0.33)$ & $0.026(0.016-0.036)$ & $<0.0001$ \\
$\begin{array}{l}\text { Third ventricle } \\
(\mathrm{mm})\end{array}$ & $13.7(12.7-14.7)$ & $12.7(11.6-13.8)$ & $1.000(0.480-1.520)$ & $<0.001$ \\
\hline
\end{tabular}
operatively (Pc1 - Pc3). There was no gravity effect (Pc2 - Pc3).

Figure 4 shows the results for the six patients. In patients $29-32$ the CSF pressures decreased postoperatively. There was no gravity effect. The sigma shaped correlation between pressure $v$ flow described by the manufacturer occurred in patients 30 and 31 . In patient 32 the pressure $v$ flow curve was similar to the preoperative drainage of CSF by natural pathways.

In patients 33 and 34, there was no reduction in CSF pressure postoperatively and no gravity effect. The $S$ shaped pressure $v$ flow curve was seen, but the flow was about the same as preoperatively despite high differential valve pressures. These shunts were not functioning.

\section{OVERALL CLINICAL OUTCOME RELATED TO} SHUNT FUNCTION

Six patients' shunts (patients 26, 27, 28, 32, 33, 34; figs $3 \mathrm{D}$ and 4) were not functioning according to the CSF dynamic tests. Despite this, four of the patients were improved after the operation. In the 28 patients with functioning shunts, gait was markedly improved in 11 , slightly improved in 10 , and unchanged in seven. According to the MMSE, 13 patients improved $\geqslant$ the upper $95 \%$ CI (two points), 12 were unchanged, and three deteriorated.

The relation between clinical improvement and $P c 1, P c 2$, and $P c 3$ was assessed. The Pc2 was positively related to improvement in MMSE (linear regression $r^{2}=0.38 ; \quad P=$ 0.0005). The Pc2 tended to be higher in patients with a marked improvement of gait (ANOVA $\mathrm{P}=0.07$ )

\section{WIDTH OF THE VENTRICLES}

Size of the lateral and third ventricles decreased significantly postoperatively (table 2). Nine patients had a pronounced reduction in the ventricular index ( $\geqslant$ upper $95 \% \mathrm{CI}$ ). According to the CSF dynamics, seven of these shunts were functioning (patients 5,6 , $13,14,20,21,30)$ and two non-functioning (patients 32, 33). Seven patients had no change or an increased width of the lateral ventricles postoperatively. All of these had functioning shunts according to the CSF dynamics (patients $3,8,10,11,16,19,22$ ). There were no correlations between the size of the ventricles and $\mathrm{Pc} 1, \mathrm{Pc} 2$, or Pc3. Nor was there any correlation between improvement in gait or MMSE and the indices of the ventricles.

\section{Discussion}

There is a pressing need for a criterion standard for assessing the function of CSF shunts. In bench tests, CSF infusion methods are the natural choice. ${ }^{4611123839}$ In our opinion, a similar method should be used in shunted patients. Measurements of resistance $e^{40}$ or intracranial pressure in relation to body position ${ }^{9}$ as indicators of shunt function have been used. A systematic investigation of a homogeneous patient population preoperatively and postoperatively, however, with respect to CSF dynamics, shunt function and outcome of surgery has never been made. The purpose of the preoperative CSF dynamic investigation was to assess CSF pressure and
Figure 4 CSF dynamics of Orbis Sigma shunts. before and after operation. For further explanations see the materials and methods section.

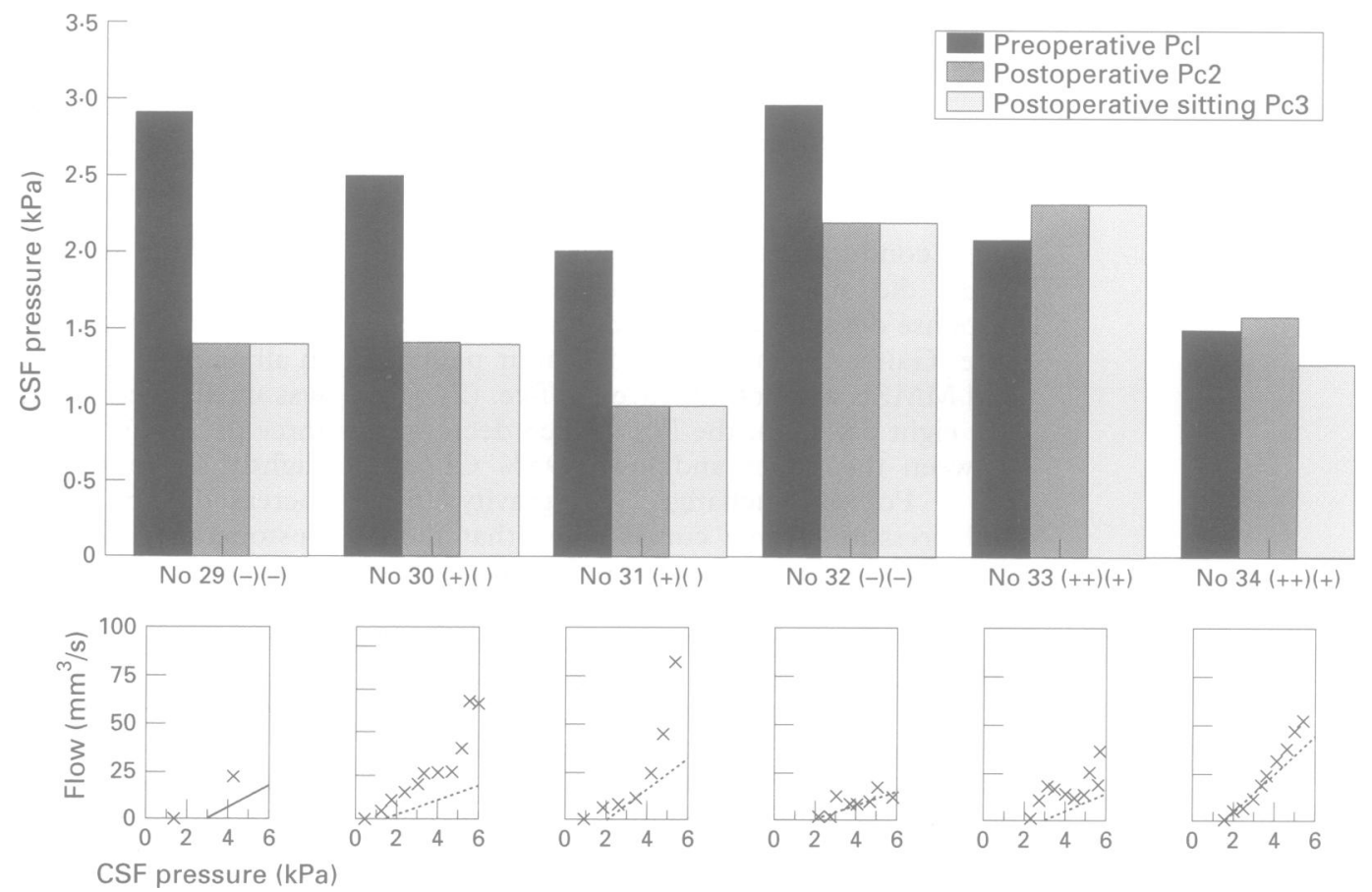



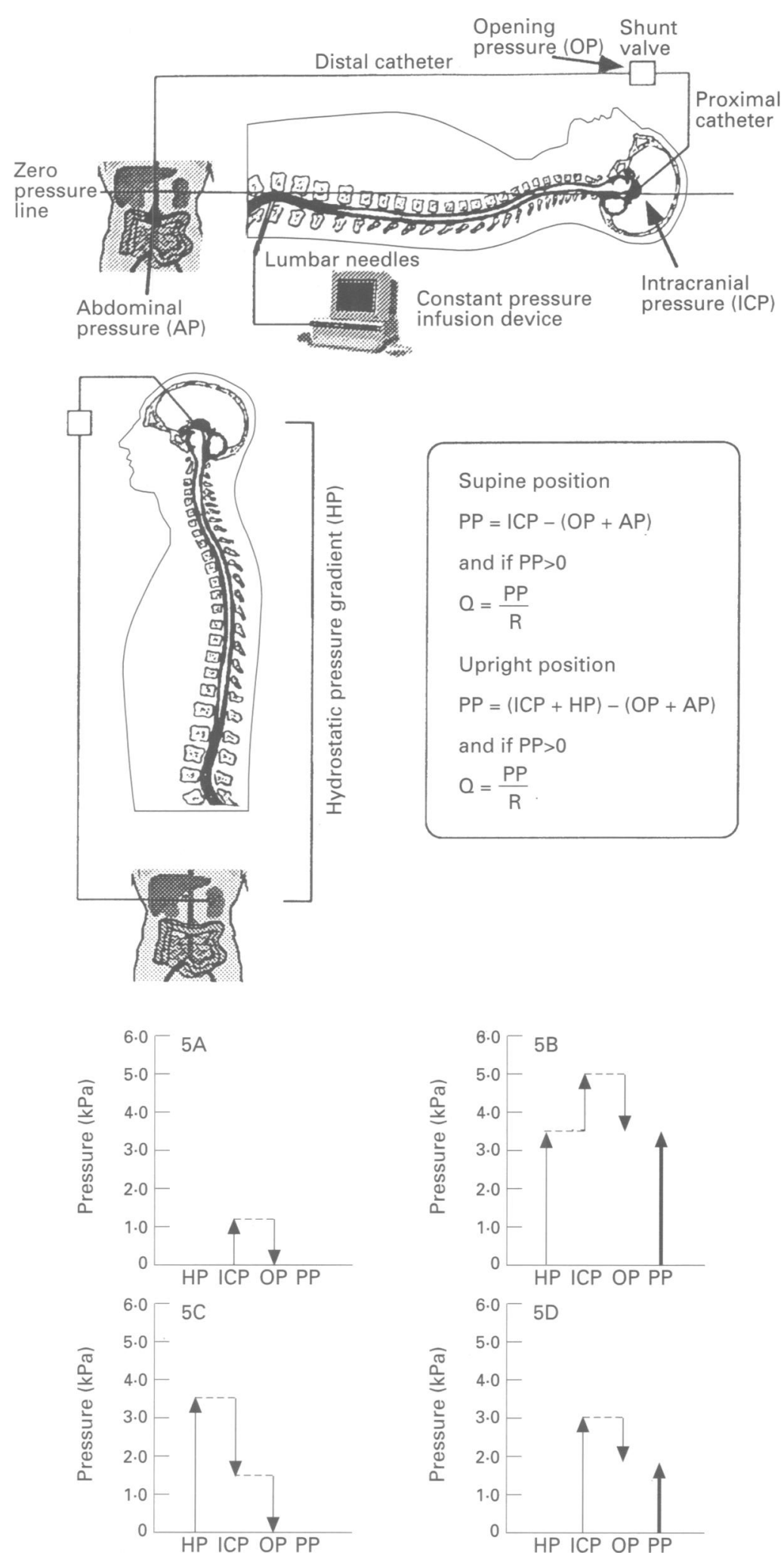

conductance. In our experience, the conductance does not predict the outcome of surgery, although it is reduced in patients with IAHS. $^{29}$ It is unlikely that a patient with IAHS with a high conductance (low resistance) would be improved by a shunt (patient 10).

The purpose of a shunt is to facilitate the CSF outflow and lower the CSF pressure. The dynamics of CSF shunts suggests that the
Figure 5 Schematic drawing of shunt dynamics. The cranial sagittal centre is the zero pressure reference level. The peritoneal pressure is presumed to be zero. $(A)$ Equilibrium in the supine position. CSF formation is equal to CSF absorption and the hydrostatic pressure is zero. The opening pressure will balance the CSF pressure. There is no perfusion pressure and no net CSF flow. (B) Standing up. The hydrostatic pressure is added to the intracranial pressure (minus the opening pressure of the shunt). There is a net CSF flow because of the resulting perfusion pressure. There will be a flow through the shunt until the perfusion pressure is zero. (C) Equilibrium in the standing position. Because of CSF flow, the intracranial pressure decreases or even becomes negative. The perfusion pressure declines and when it reaches zero CSF flow is minimised. (D) Constant pressure infusion method. During the CSF infusion test, the patient is supine. The hydrostatic pressure is zero and the peritoneal pressure is presumably the same. The perfusion pressure is settled by the CSF pressure (which could be altered by lumbar $C S F$ infusion) and the opening pressure of the shunt. Multiple pressurelflow levels can be obtained. ICP = intracranial pressure; $H P=$ hydrostatic pressure; $O P=$ opening or closing pressure of the shunt; $P P=$ perfusion pressure of $C S F$ (the driving force of CSF); $A P=$ abdominal pressure; $Q=C S F$ flow; $R=$ resistance in the shunt system.

postoperative CSF pressure (Pc2) should never exceed the opening pressure of the shunt (fig 5A). According to the manufacturer's specifications, the opening pressure of a medium differential pressure valve should be $1.2 \mathrm{kPa}$; however, Pc2 went below $1.5 \mathrm{kPa}$ in just one patient (5) and the preoperative and postoperative mean CSF pressures (Pc1 - Pc2) did not differ. Figure 3A shows the patients in whom the opening pressure of the shunt was below the preoperative CSF pressure (Pc1) but exceeded $1 \cdot 2 \mathrm{kPa}$. In the remaining patients with a functioning shunt the opening pressure exceeded or was equal to Pc1 and explains why Pc2 remained unchanged (fig 3B). A considerable between patient variation in postoperative CSF pressures (Pc2) was seen in patients with differential pressure shunts, though similar shunt devices had been implanted. In patients with functioning variable resistance shunts (patients 29-31), there was a more marked decline in CSF pressure compared with the differential pressure shunts (table 1). The Pc2 was below $1.5 \mathrm{kPa}$ in all patients.

Drainage of CSF through the shunt at different pressures as well as the opening pressure of the shunt can be determined when a constant pressure infusion method is used. If there is no drainage through the shunt, the pressure flow curve is flat and similar to the preoperative conductance. As the opening pressure is exceeded, the flow increases linearly with pressure. Despite the aforementioned variations of opening pressure in differential pressure shunts, most had a linear pressure flow relation according to their specifications (fig 3A-C) when opening pressure was exceeded. The corresponding curve of the variable resistance valve should consist of three intervals of differential pressures, each giving different amounts of CSF drainage. We could only confirm a similar pattern in three of six patients (fig 4 ; patients $30,31,33$ ). Recently, the construction of the variable resistance valve (Cordis Orbis-Sigma) shunt has been criticised. ${ }^{5}$ 
When patients are standing, CSF flows in the tubing between the ventricles and the abdominal cavity because of an increased hydrostatic pressure (fig 5B). After an interval of disequilibrium, the flow is counterbalanced by the differential pressure of the valve and a decreased or even negative intracranial pressure (fig $5 \mathrm{C}$ ). The siphoning effect is most often considered as an unwanted consequence of the shunting, resulting in adverse events. In the present study, a gravity induced flow was seen in most of the differential pressure valves but never in a variable resistance valve. The gravity induced flow was of fundamental importance in lowering the CSF pressure (Pc1 - Pc3; table 1) in most patients with differential pressure shunts. No adverse events were caused by a low CSF pressure $(\mathrm{Pc} 3<1 \mathrm{kPa})$ in the first three months.

The Pc2 increased in some patients with differential pressure valves (fig 3C). This may be explained by a gravity induced flow. Most patients are upright for most of the day and the siphoning effect will prevent drainage through the natural outflow pathways. This could leave the arachnoidal villi in an off state during the supine position at night and cause a further reduction in conductance.

Six patients in the present study had nonfunctioning shunts (figs $3 \mathrm{D}$ and 4). Despite this, four of these six had an improved gait and two had improved MMSE scores. The improvement in gait was transient in three of these patients. It is known that non-shunted patients with IAHS may improve weeks or months after a CSF tap. ${ }^{24243}$ Temporary improvement after shunt implantation has been outlined. ${ }^{44}$ The rationale may be that the shunt dysfunction comes near to the CSF dynamic investigation. Gait and MMSE scores failed to improve in patients with functioning shunts (patients 10,16,17, 29), probably because of irreversible brain damage. Decrease in ventricle width is often taken as evidence of shunt function. The present study, however, showed no relation between width of ventricles, shunt function, or clinical improvement.

Ascertainment of differential pressure valve (Cordis Hakim standard system) function by the CSF infusion technique clearly showed that the valve system in vivo did not behave according to the specifications provided by the manufacturer. In terms of gravity effect and the pressure flow curves, a CSF flow and a decrease in CSF pressure is achieved at least in the upright position and apparently suffices to ameliorate the clinical symptoms to some extent in most of the patients. Shunt failure was common in the variable resistance valve (Cordis Orbis-Sigma). The properties of the functioning shunts seem to be satisfactory.

We thank Lars-Johan Liedholm, Lars Forsgren, Håkan Fridén, and Göran Eriksson for helpful discussion and comments on the text of this article. The study was supported by Karl-Oskar Hansson's foundation, the Swedish Society of the Neurologically Disabled (NHR), and Norriandsfonden.
1 Adams R, Fisher C, Hakim S, Ojemann R, Sweet W, Symptomatic occult hydrocephalus with "normal" cerebrospinal-fluid pressure. N Engl f Med 1965;273: 117-26.

2 Hakim S, Adams R. The special clinical problem of symptomatic hydrocephalus with normal cerebrospinal fluid pressure. $\mathcal{F}$ Neurol Sci 1965;2:307-27.

3 Sainte-Rose C, Piatt JH, Renier D, et al. Mechanical complications in shunts. Pediatr Neurosurg 1991;17:2-9.

4 Aschoff A. In-vitro-Testung von Hydrocephalus-Ventilen. Thesis. Heidelberg: University of Heidelberg 1994.

5 Trost HA, Heissler HE, Claussen G, Gaab MR. Testing the hydrocephalus shunt valve: long-term bench test the hydrocephalus shunt valve: long-term bench test for a model for testing valves under physiological condifor a model for testing valves under physiological

6 Ekstedt J, Fridén H. Hydrodynamic properties of CSF shunt systems. In: Shulman K, Marmarou A, Miller JD, Becker DP, eds. Intracranial Pressure IV. Berlin: Springer-Verlag, 1980:483-8.

7 Chapman PH, Cosman ER, Arnold MA. The relationship between ventricular fluid pressure and body position in normal subjects and subjects with shunts: a telemetric study. Neurosurgery 1990;26:181-9.

8 Foltz EL, Blanks JP. Symptomatic low intracranial pressure in shunted hydrocephalus. $f$ Neurosurg 1988;68: $401-8$.

9 Fox JL, McCullough DC, Green RC. Effect of cerebrospinal fluid shunts on intracranial pressure and on cerebrospinal fluid dynamics. $f$ Neurol Neurosurg cerebrospinal fluid dynamid

10 Pudenz RH, Foltz EL. Hydrocephalus: overdrainage by ventricular shunts. A review and recommendations. Surg Neurol 1991;35:200-12.

11 International Organization for Standardization. New working document on neurosurgical implants-sterile, single-use hydrocephalus shunts and components. Pforzheim: DIN Germany, 1992.

12 American Society for Testing and Materials. Standard practice for evaluating and specifying implantable shunt assemblies for neurosurgical application. In: Annual Book of ASTM Standards. New York: American National Standards Institute, 1989:647-79.

13 Piatt J. Physical examination of patients with cerebrospinal fluid shunts: is there useful information in brospinal fluid shunts: is there useful inform
pumping the shunt? Pediatrics 1992;89:470-3.

14 Martin AJ, Drake JM, Lemire C, Henkelman RM. Cerebrospinal fluid shunts: flow measurements with MR maging. Radiology 1989;173:243-7.

15 Frank E, Buonocore M, Hein L. Magnetic resonance imaging analysis of extremely slow flow in a model shunt system. Childs Nerv Syst 1992;8:73-5.

16 Savader SJ, Savader BL, Murtagh FR, Clarke LP, Silbiger ML. MR evaluation of flow in a ventricular shunt phantom with in vivo correlation. $\mathcal{F}$ Comput Assist Tomogr 1988;12:765-9.

17 Chadduck WM, Crabtree HM, Blankenship JB, Adametz J. Transcranial Doppler ultrasonography for the evaluation of shunt malfunction in pediatric patients. Childs Nerv Syst 1991;7:27-30.

18 Borbély $\mathrm{K}$, Simkovics $\mathrm{M}$, Paraicz E, Pásztor E. Scintigraphic study of cerebrospinal fluid shunts. Acta Scintigraphic study of cerebrospinal

19 Howman-Giles R, McLaughlin A, Johnston I, Whittle I. A radionucleotide method of evaluating shunt function and CSF circulation in hydrocephalus. $f$ Neurosurg 1984;61:604-5

20 Reilly PL, Savage JP, Doecke L. Isotope transport studies and shunt pressure measurements as a guide to shunt function. $B r \mathcal{F}$ Neurosurg 1989:3;681-90.

21 Vanneste J, Augustijn P, Tan WF, Dirven C. Shunting normal pressure hydrocephalus: the predictive value of combined clinical and CT data. $₹$ Neurol Neurosurg Psychiatry 1993;56:252-6.

22 Greenberg J, Shenkin H, Adams R. Idiopathic normal pressure hydrocephalus-a report of 73 patients. pressure hydrocephalus-a report of 73

23 Børgesen S, Gjerris F. The predictive value of conductance to outflow of CSF in normal pressure hydrotance to outfiow of CSF in norn

24 Fisher CM. Hydrocephalus as a cause of disturbances of gait in the elderly. Neurology 1982;32:1358-63.

25 Petersen R. Surgical treatment of idiopathic hydrocephalus in elderly patients. Neurology 1985;35:307-11.

26 Vassilouthis $J$. The syndrome of normal-pressure hydrocephalus. F Neurosurg 1984;61:501-9.

27 Laws ER, Mokri B. Occult hydrocephalus: results of shunting correlated with diagnostic tests. Clin Neurosurg 1977;24:316-33.

28 Black P, Ojemann R, Tzouras A. CSF shunts for dementia, incontinence and gait disturbance. Clin Neurosurg 1985;32:632-51.

29 Malm J, Kristensen B, Karlsson T, Fagerlund M, Elfverson J, Ekstedt J. The predictive value of CSF hydrodynamic tests in patients with the idiopathic adult hydrocephalus syndrome. Arch Neurol 1995 (in press).

30 Ekstedt J, CSF hydrodynamic studies in man. 1. Method of constant pressure CSF infusion. $f$ Neurol Neurosurg of constant pressure CSF
Psychiatry 1977;40:105-19.

31 Ekstedt J, Fridén H. Estimation of CSF outflow resistance in humans: infusion methods. In: Gjerris F, Børgesen S, Soelberg Sørensen P, eds. Outflow of cerebrospinal
fluid. Copenhagen: Alfred Benzon foundation, 1989: fluid. Cop. 
32 Kristensen B, Malm J, Markgren P, Ekstedt J. CSF hydrodynamics in superior sagittal sinus thrombosis. $f$ Neurol dynamics in superior sagittal sinus th

33 Nutt JG, Marsden CD, Thompson PD. Human walking and higher-level gait disorders, particularly in the elderly. Neurology 1993;43:268-79.

34 Graff-Radford NR, Godersky JC. Normal-pressure hydrocephalus. Onset of gait abnormality before dementia predicts good surgical outcome. Arch Neurol 1986;43: 940-2.

35 Folstein MF, Folstein SE, McHugh PR. Mini-mental state: a practical method for grading the cognitive status of patients for clinicians. F Psychiatr Res 1976;12: of patients

36 Hanson J, Levander B, Liliequist B. Size of the intracerebral ventricles as measured with computer tomography,
encephalography and echoventriculography. Acta Radiol 1978;suppl 346:98-106.

37 Sall $\mathrm{J}, \mathrm{Ng} \mathrm{K}$, Hecht $\mathrm{M}$. $\mathfrak{F M P}$. Cary: SAS Institute Inc,

38 Sainte-Rose C, Hooven MD, Hirsch J-F. A new approach in the treatment of hydrocephalus. $f$ Neurosurg 1987 ; 66:213-26.

39 Watts C, Keith HD. Testing the hydrocephalus shunt valve. Childs Brain 1983;10:217-28.

40 Czosnyka M, Maksymowicz W, Batorski L, Koszewski W, Czosnyka Z. Comparison between classic-differential and automatic shunt functioning on the basis of infusion test. Acta Neurochir (Wien) 1990;106:1-8.

41 Costabile G, Probst C. Intrathecal infusion tests and decrease in shunt revisions and infections. Neurochirurgia 1988;31:134-5.

42 Fisher CM. Communicating hydrocephalus. Lancet 1978; 7:37.

43 Wikkelsø C, Andersson H, Blomstrand C, Lindqvist G. The clinical effect of lumbar puncture in normal pressure hydrocephalus. $\mathcal{F}$ Neurol Neurosurg Psychiatry 1982; 45:64-9.

44 Vanneste J, Augustijn P, Dirven C, Tan WF, Goedhart ZD. Shunting normal-pressure hydrocephalus: do the benefits outweigh the risks? A multicenter study and literature review. Neurology 1992;42:54-9. 